\title{
Oily Multifocal IOL
}

\section{Amber Amar Bhayana ${ }^{*}$, Priyanka Prasad ${ }^{1}$}

${ }^{1}$ Senior Resident, Dr. RP Centre for Ophthalmic Sciences, AIIMS, New Delhi, India

*Corresponding Author: Amber Amar Bhayana, Senior Resident, Dr. Rajendra Prasad Centre for Ophthalmic Sciences, All India Institute of Medical Sciences, New Delhi, India; Email: amber.amar.bhayana@gmail.com

Received Date: 06-10-2020; Accepted Date: 16-10-2020; Published Date: 23-10-2020

Copyright $^{\odot} 2020$ by Bhayana AA, et al. All rights reserved. This is an open access article distributed under the terms of the Creative Commons Attribution License, which permits unrestricted use, distribution, and reproduction in any medium, provided the original author and source are credited.

\section{Clinical Image}

A 58 year old male operated for cataract surgery implanted with a multifocal Intraocular Lens (IOL), later underwent vitreoretinal surgery for retinal detachment with silicone oil injection. Even after removal of silicone oil, the patient had oil deposits in the groves between the multifocal IOL as shown in the Fig. 1. Multifocal IOLs are indeed a bad choice for patients who require treatment for retinal disorders because not only fundus visualization is difficult in these patients due to multifocal refractive/diffractive phenomenon but also the groves might become a niche for oil deposition.
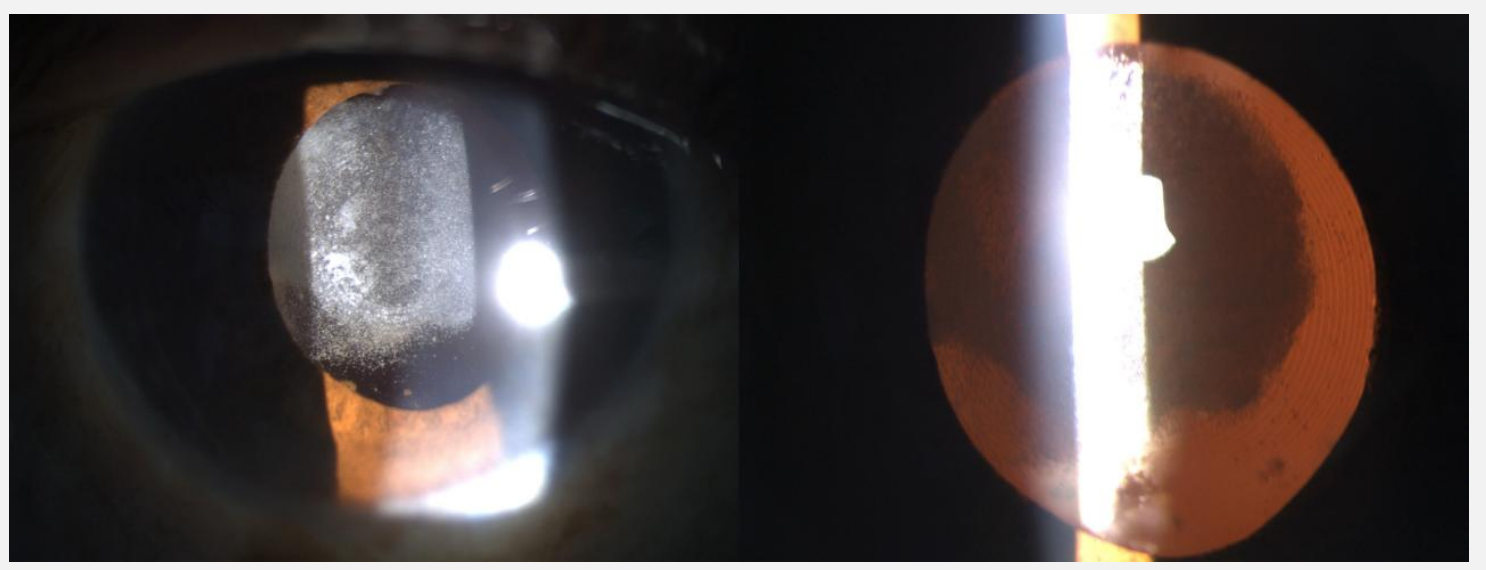

Figure 1: Oil deposits in the groves Multifocal IOL. 